\title{
Sasirangan Motifs Classification using Scale- Invariant Feature Transform (SIFT) and Support Vector Machine (SVM)
}

\author{
Muhammad Alkaff ${ }^{1, *}$, Husnul Khatimi ${ }^{1}$, Nur Lathifah $^{1,}$ and Yuslena Sari ${ }^{1}$ \\ ${ }^{1}$ Information Technology, Faculty of Engineering, Lambung Mangkurat University, Indonesia
}

\begin{abstract}
Sasirangan is one of the traditional cloth from Indonesia. Specifically, it comes from South Borneo. It has many variations of motifs with a different meaning for each pattern. This paper proposes a prototype of Sasirangan motifs classification using four (4) type of Sasirangan motifs namely Hiris Gagatas, Gigi Haruan, Kulat Kurikit, and Hiris Pudak. We used primary data of Sasirangan images collected from Kampung Sasirangan, Banjarmasin, South Kalimantan. After that, the images are processed using Scale-Invariant Feature Transform (SIFT) to extract its features. Furthermore, the extracted features vectors obtained is classified using the Support Vector Machine (SVM). The result shows that the ScaleInvariant Feature Transform (SIFT) feature extraction with Support Vector Machine (SVM) classification able to classify Sasirangan motifs with an overall accuracy of $95 \%$.
\end{abstract}

\section{Introduction}

Indonesia has many forms of cultural heritage, and one of them is traditional cloth. The most well known traditional cloth from Indonesia is Batik because it recognized by UNESCO as the cultural heritage from Indonesia since 2009 [1]. In addition to Batik, Indonesia also has a traditional cloth heritage derived from South Kalimantan named Sasirangan. Sasirangan is also known to have variants of patterns or motifs that have a different meaning for each one of them. Although Sasirangan often used in formal events in South Kalimantan, over time most people no longer care about the traditional motifs that exist in Sasirangan that they wear. Moreover today, only a few people have the expertise to recognize many motifs found in Sasirangan. Therefore, efforts should be made to preserve Sasirangan as a native culture of South Kalimantan.

Some Sasirangan motifs have been registered in Directorate General of Copyright (Dirjen HAKI) such as Hiris Pudak, Kambang Kacang, Bayam Raja, Kulat Kurikit, etc. [2]. Unfortunately, only a few motifs of Sasirangan that registered on Dirjen HAKI can be found in Kampung Sasirangan, whereas Kampung Sasirangan was known as a center for Sasirangan artisans in South Kalimantan. The most common motifs that can be seen in Kampung Sasirangan is Hiris Gagatas and Gigi Haruan which unfortunately not registered as Sasirangan motifs in Dirjen HAKI. There are also some new and modern motifs of

* Corresponding author: m.alkaff@ulm.ac.id 
Sasirangan sold by craftsmen in Kampung Sasirangan. Therefore, we need to do something to conserve the traditional motifs of Sasirangan.

There have been some studies on pattern recognition and classification of traditional cloth motif, but they mostly conducted on Batik. The most common feature extraction method used for Batik motif is Gray Level Co-Occurrence Matrices (GLCM) [3]-[6]. Based on studies that compare the performance of feature extraction methods, it is shown that GLCM bested Canny Edge Detection and Gabor Filters on classifying Batik motifs. However, research on the classification of food images by Chen [7] shows that GLCM performs well on single items or similar foods while SIFT performs well on complicated dishes. Therefore, in this study, we use the SIFT method to extract features from Sasirangan motifs because we consider most of the Sasirangan motifs are complex.

Furthermore, there has been little research on Sasirangan motif recognition or classification. We could find only one study of Sasirangan pattern recognition from Google Scholar. This research used the Template Matching method to match some of the Sasirangan motifs. The results show that this method can recognize 25 of $30(83.33 \%)$ images of Sasirangan motifs [8].

Several classification methods of Batik motif used in some studies. Setyawan et all. [9], used SIFT and k-Nearest Neighbor to classify Batik motifs but the average overall accuracy only reached $31.43 \%$ for seven classes of Batik motifs. Suciati [10] used the Backpropagation Neural Network (BPNN) with Color-Texture-Based Feature Extraction to classify seven groups of Batik motifs with the rate of 0.37 Tanimoto Distance. Aditya et al. [11], also used BPNN in combination with GLCM and comes with some promising results of more than $90 \%$ precision rate. Meanwhile, Azhar et al. [12] used SIFT with Support Vector Machine (SVM) classifier on Batik motifs. The results show that the average accuracy reached $97.67 \%, 95.47 \%$ and $79 \%$ on a normal image, rotated image and scaled image, respectively.

Accordingly, this study will use four (4) class of Sasirangan motifs namely Hiris Gagatas, Gigi Haruan, Kulat Kurikit, and Hiris Pudak. We collected the images from Kampung Sasirangan, a center of Sasirangan market in Banjarmasin, South Kalimantan. We employ SIFT methods to extract features from Sasirangan motifs images. Subsequently, the feature vectors obtained from the images will be processed using SVM to classify Sasirangan motifs for each class.

\section{Sasirangan}

Sasirangan is a traditional cloth of the Banjarese Tribe from South Kalimantan. Historically, sasirangan serve as a means of treatment of several diseases such as abdominal pain, headaches, fever, mental illness, and even supernatural disorder. It requires people with the disease to wear sasirangan fabric regularly. Some traditional healer guides this treatment of disease, and it is called "Batamba.". The term sasirangan relates to the technique of drawing and coloring. First, the cloth used is a plain white cloth, then the fabric is sewn by following the pattern of vertical lines. The fabric is then immersed in a dye-filled bath, then dried. Once dry, the stitches opened, and the fabric becomes Sasirangan [13].

The hallmark of the sasirangan is a series of motifs which generally arranged in vertical form; the motifs rarely arranged in horizontal form. Below are some of Sasirangan's motifs taken from the book "Sasirangan: kain khas Banjar" by Syamsiar Seman. 
a. Gigi Haruan

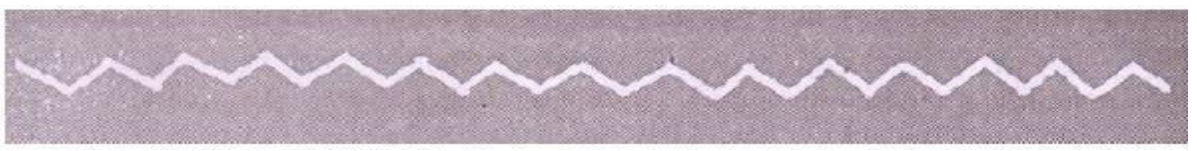

Fig. 1. Gigi Haruan [13]

b. Kulat Kurikit

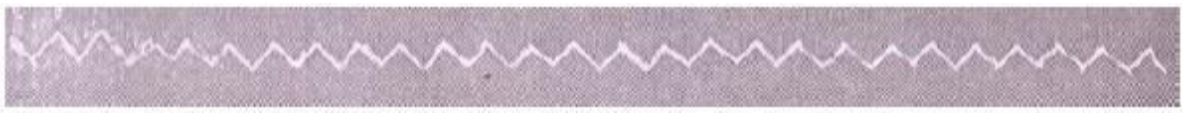

Fig. 2. Kulat Kurikit [13]

c. Hiris Pudak

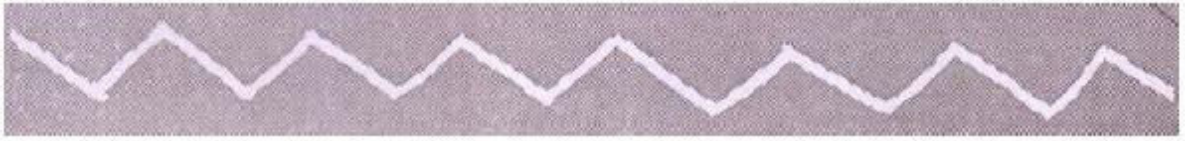

Fig. 3. Hiris Pudak [13]

d. Ular Lidi

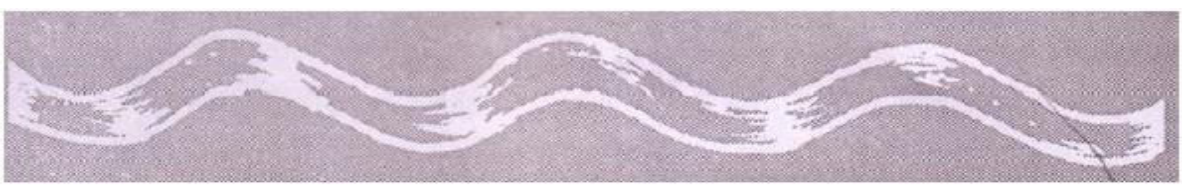

Fig. 4. Ular Lidi [13]

e. Kambang Kacang

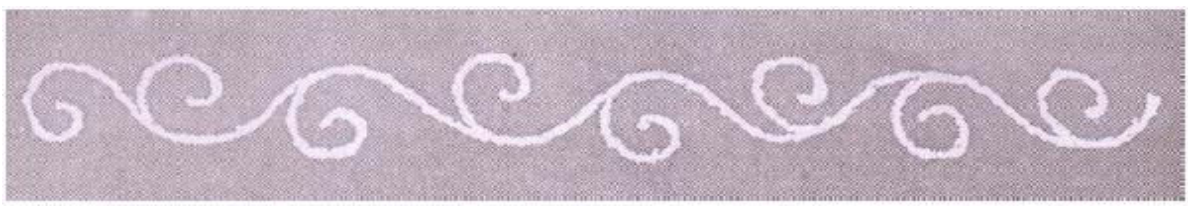

Fig. 5. Kambang Kacang [13]

f. Hiris Gagatas

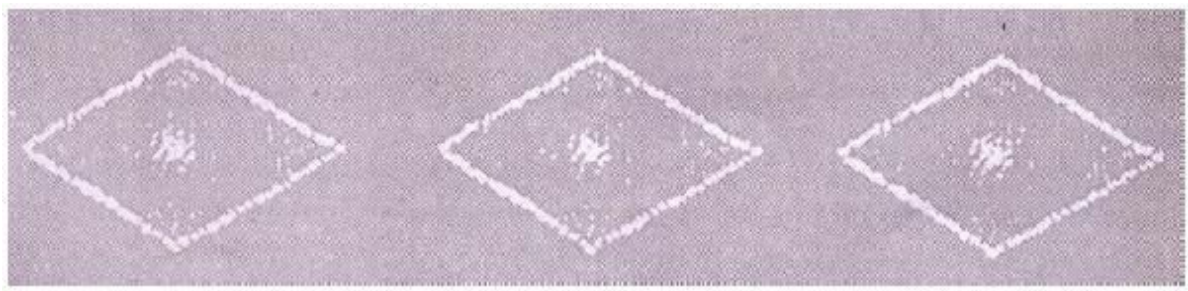

Fig. 6. Hiris Gagatas [13] 
g. Kambang Sakaki

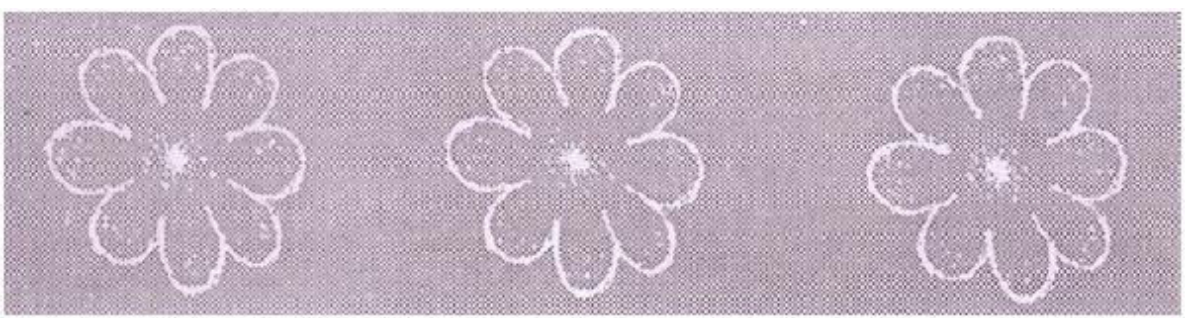

Fig. 7. Kambang Sakaki [13]

h. Ombak Sinapur Karang

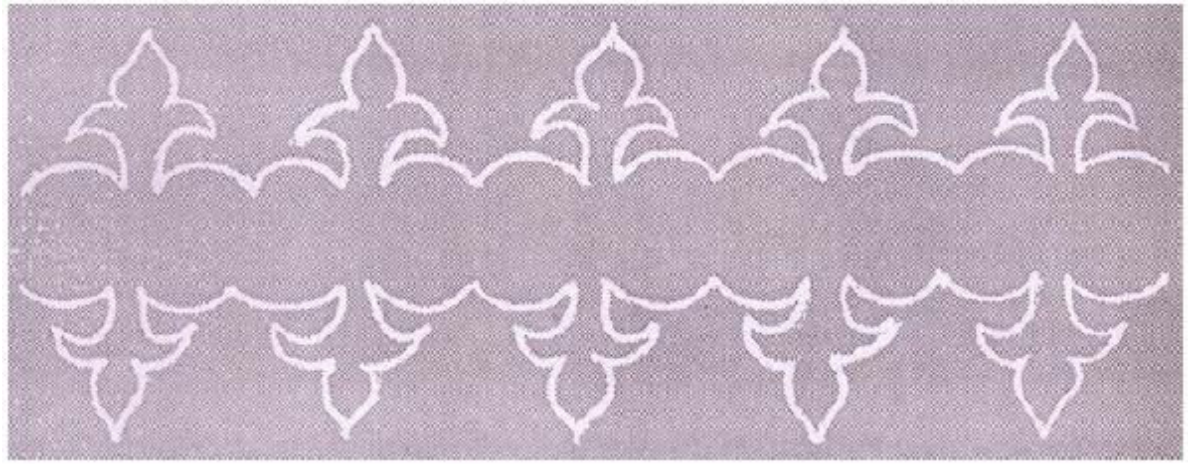

Fig. 8. Ombak Sinapur Karang [13]

i. Bayam Raja

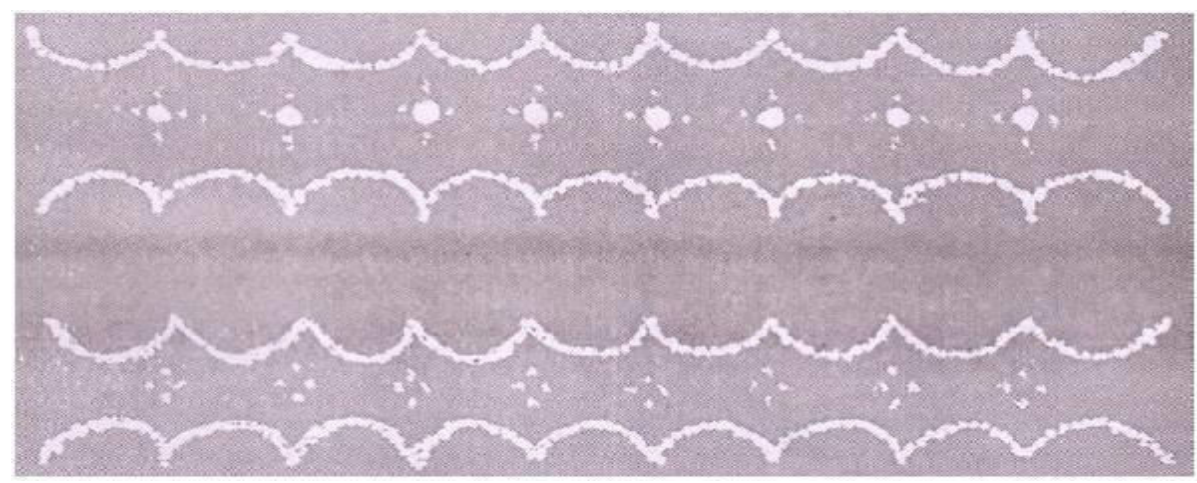

Fig. 9. Bayam Raja [13]

\section{Material and Methods}

\subsection{Data Collection}

In this study, we use four motifs of Sasirangan that is Hiris Gagatas, Gigi Haruan, Kulat Kurikit, and Hiris Pudak. We use those motifs because they are the most common motif of 
Sasirangan that we could find in Kampung Sasirangan. Other motifs of sasirangan are quite hard to find in the sasirangan fabric that sold in Kampung Sasirangan.

We took the images of the sasirangan motif from several stores in Kampung Sasirangan using Canon 1100d DSLR camera with sasirangan cloth strung out and aligned with the camera. We collect 40 images for each motif yielding a total of 160 datasets of sasirangan motifs images. Below are some of the photos for each class of sasirangan motif that we used in this study.

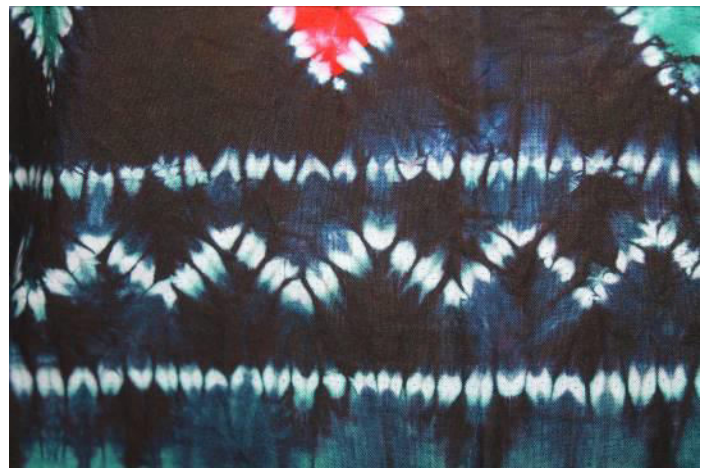

Fig. 10. Gigi Haruan motif taken from Sasirangan cloth

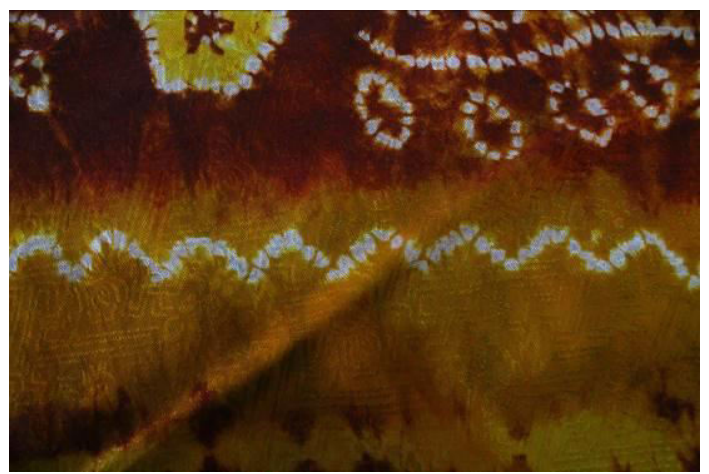

Fig. 11. Kulat Kurikit motif taken from Sasirangan cloth

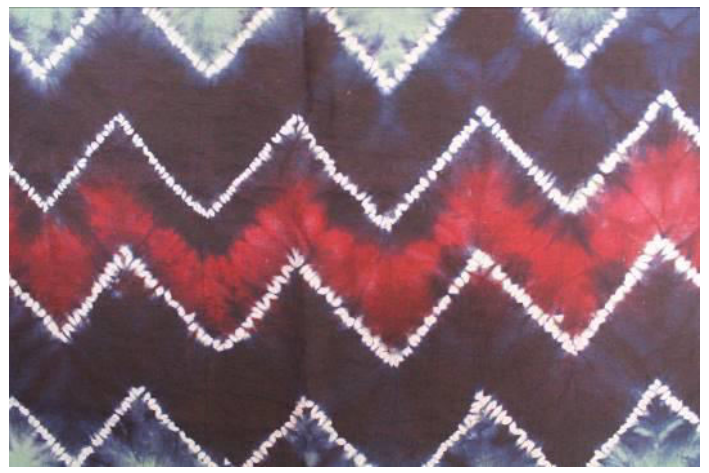

Fig. 12. Hiris Pudak motif taken from Sasirangan cloth 


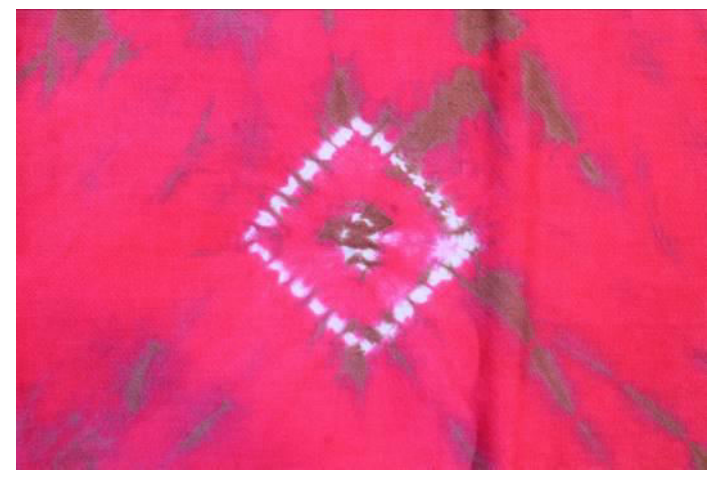

Fig. 13. Hiris Gagatas motif taken from Sasirangan cloth

\subsection{Methods}

We collected a total of 160 data of sasirangan images consisting of 40 images for each motif. We preprocessed all those images by resizing them to the size of $128 \times 128$ pixels. The feature extraction process is then performed on these images using the Scale-Invariant Feature Transform (SIFT). The process of feature extraction on the sasirangan motif using the SIFT method as seen in Fig. 14.

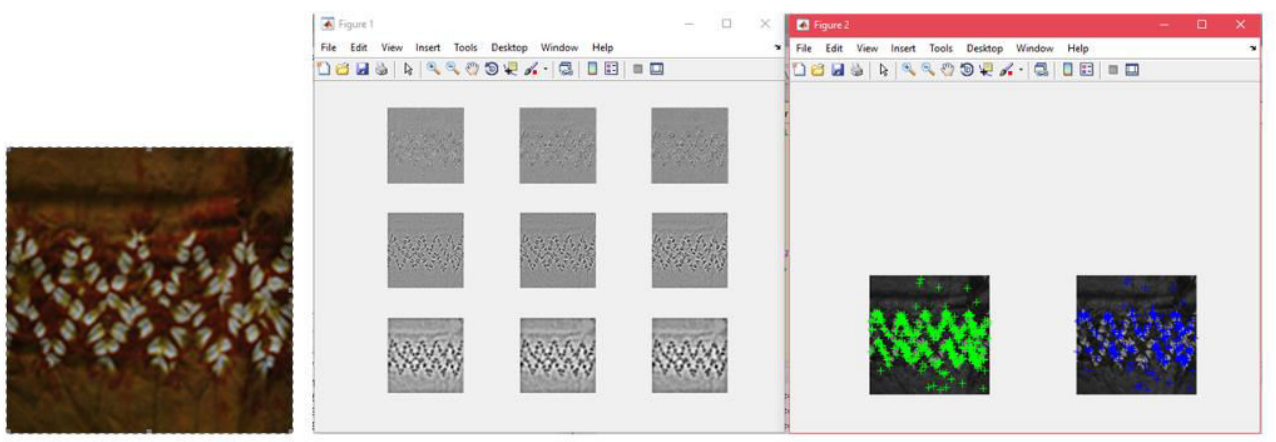

Fig. 14. Feature Extraction Process using SIFT

The datasets then divided into training sets and testing sets. The training sets containing 35 images for each class with each class label is the motif name, while the testing sets having 20 images consisting of five images for each motif. Furthermore, the training process will be conducted using a Support Vector Machine (SVM) by using the name of the sasirangan motif as a label for each class. Finally, we tested the SVM model that has been through the training process by using the images that have never been seen before by the system. A prototype will be created in the process using MATLAB 2017R2017a and VLFeat library [14] to illustrates how well the application of SIFT feature extraction and SVM classification method applied to the sasirangan images. The flow of the sasirangan motif classification system as seen in Fig. 15. 


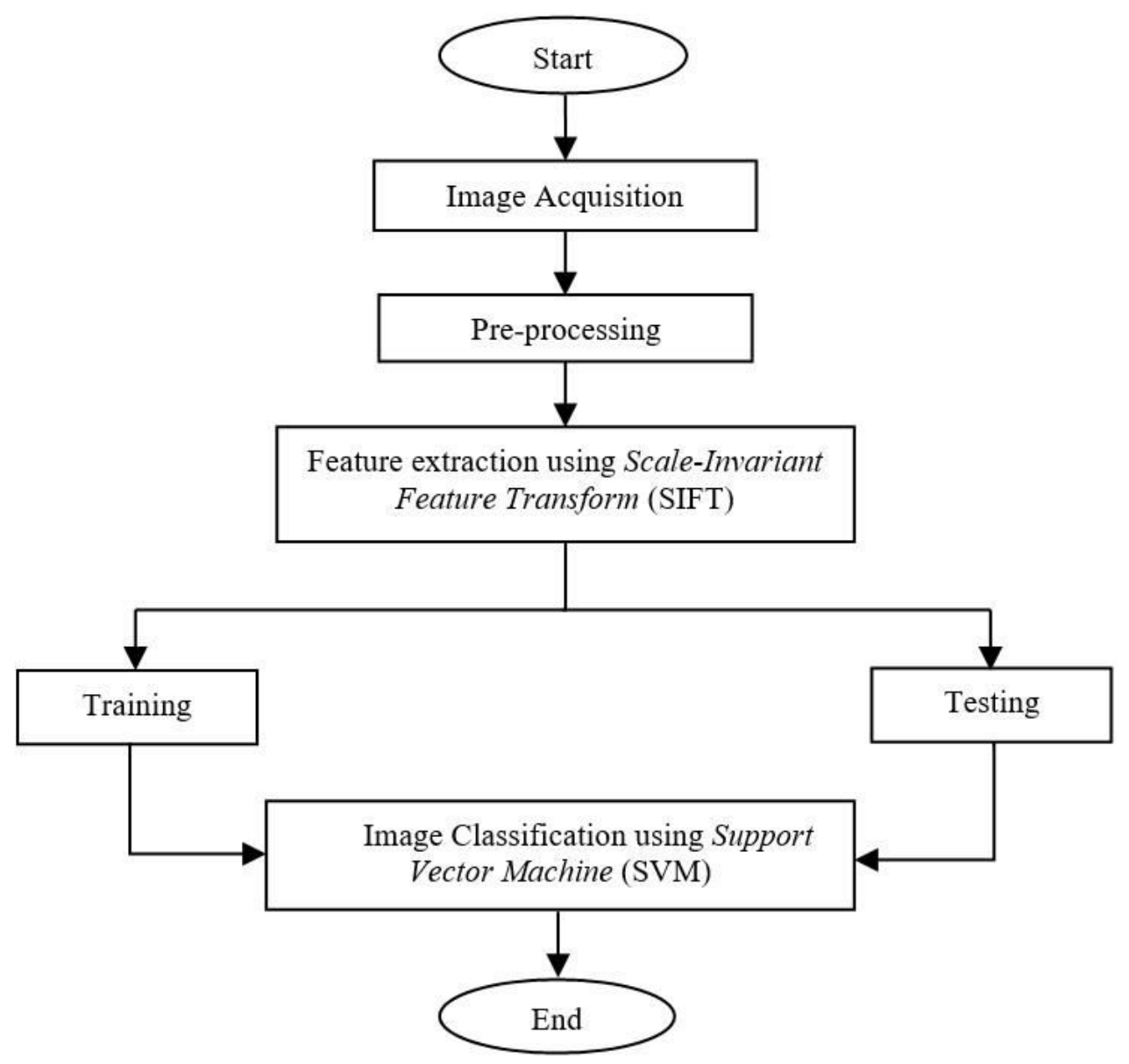

Fig. 15. The flow of the Sasirangan motif classification system

\section{Results and Discussion}

We tested the prototype using 20 images consisting of five images for each of the four classes that we want to classify. We marked the images with positive or negative depending on the class label that we are testing. For example, for classification testing on Gigi Haruan motif, we used 20 images containing five images of Gigi Haruan motifs that marked as positive and other 15 motif images are marked as negative and so on.

The results show that for Gigi Haruan, Kulat Kurikit, and Hiris Gagatas the model correctly retrieves all five images that marked as positive among 15 other images that marked as negative. On the other hand, for Hiris Pudak motif, the model correctly retrieves 4 out of 5 images that marked as positive. The results of the classification for each class shown in Fig. 16 through Fig. 19. 


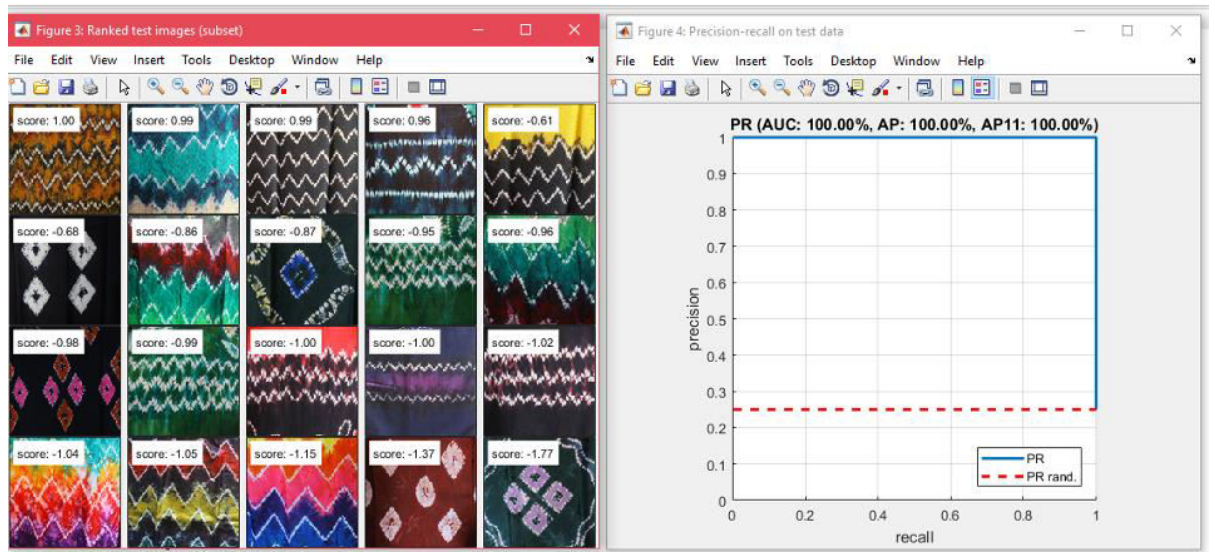

Fig. 16. Gigi Haruan motif classification results

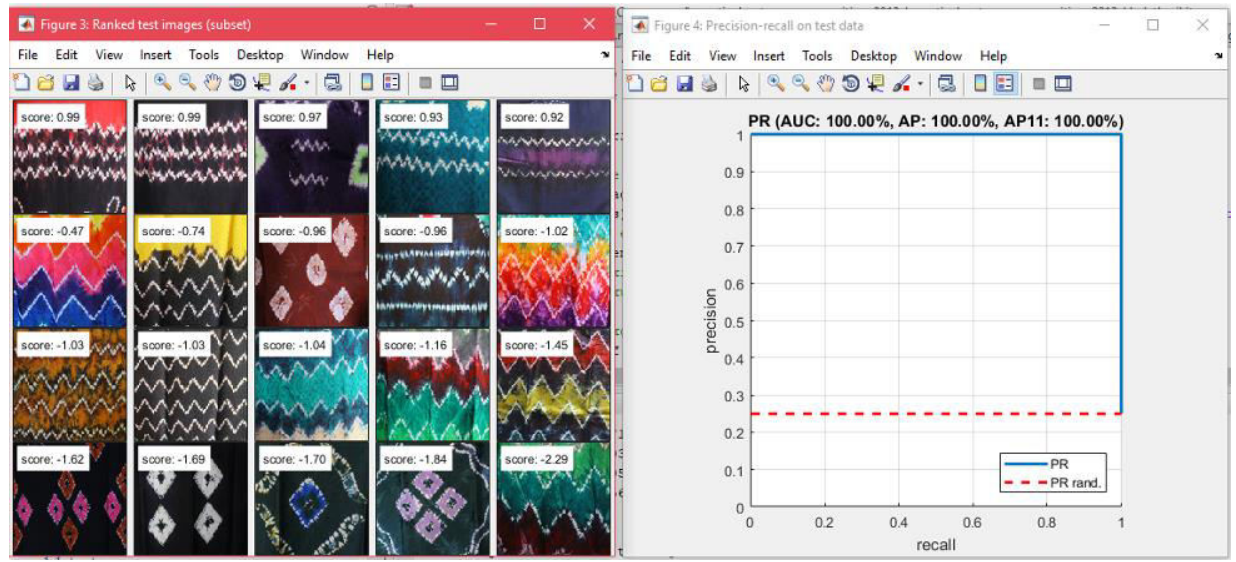

Fig. 17. Kulat Kurikit motif classification results

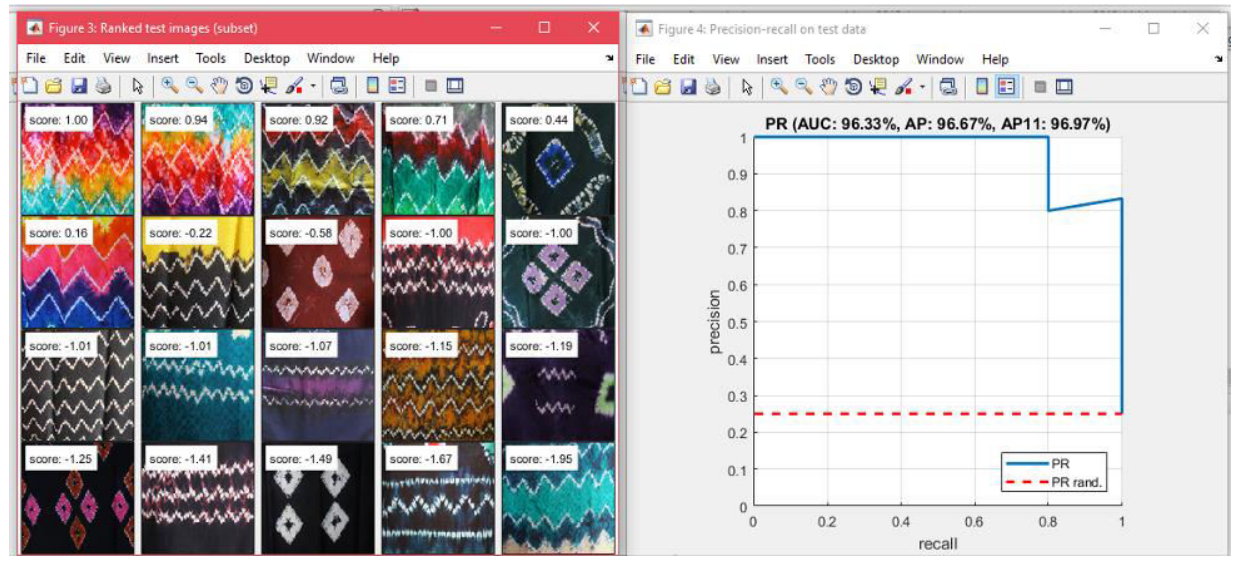

Fig. 18. Hiris Pudak motif classification results 


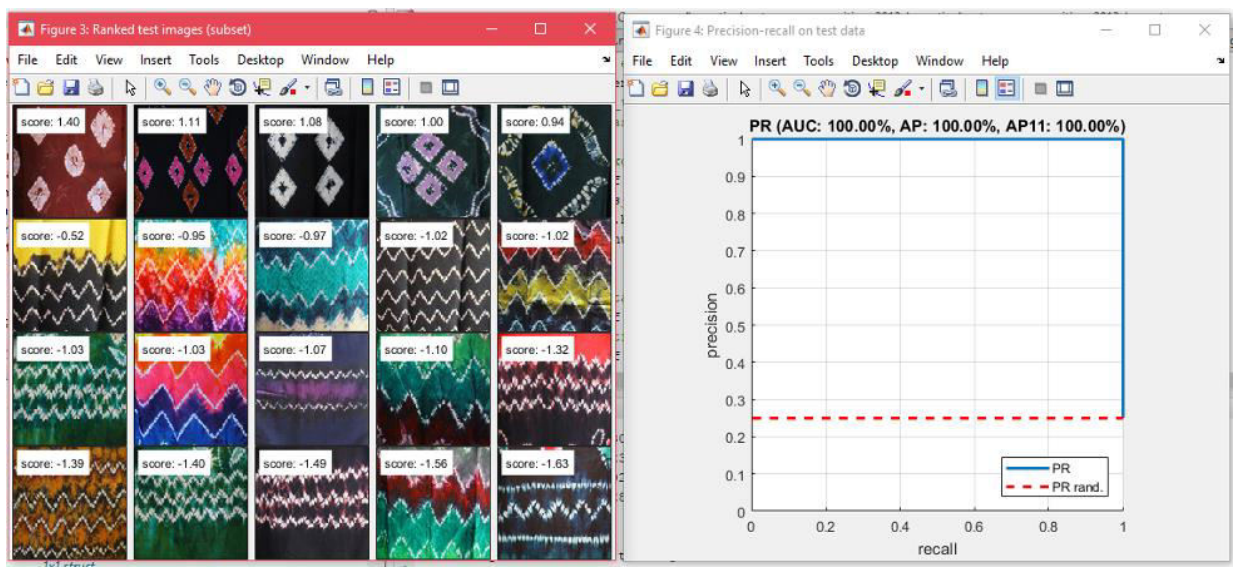

Fig. 19. Hiris Gagatas motif classification results

\section{Conclusion}

This study proposes a prototype for classifying Sasirangan motif images using Scale-Invariant Feature Transform (SIFT) feature extraction in combination with Support Vector Machine (SVM) classifier. We collected 160 datasets of Sasirangan motif images consisting of 40 images each for Gigi Haruan, Kulat Kurikit, Hiris Gagatas, and Hiris Pudak. The results of the experiment show that this prototype can classify three sasirangan motifs namely Gigi Haruan, Kulat Kurikit, and Hiris Gagatas with $100 \%$ accuracy. For other motifs that is Hiris Pudak, this system can correctly classify with $96 \%$ accuracy. This research shows that the Scale-Invariant Feature Transform (SIFT) feature extraction with Support Vector Machine (SVM) can be applied to classify Sasirangan motifs. Future work needs to use more dataset of Sasirangan motif images for more convincing results. The authors hope that this study will open up possibilities for other research on Sasirangan pattern recognition and classification.

\section{References}

1. UNESCO, "Decision of the Intergovernmental Committee: 4.COM 13.28 - intangible heritage - Culture Sector - UNESCO," Fourth Session of the Intergovernmental Committee - Abu Dhabi, United Arab Emirates, 2009. [Online]. Available: http://www.unesco.org/culture/ich/en/decisions/4.COM/13.28. [Accessed: 18-Jan2018].

2. PPID Banjarmasin, "Kain Sasirangan Banjarmasin | PPID Kota Banjarmasin." [Online]. Available: http://ppid.banjarmasinkota.go.id/2017/01/kain-sasiranganbanjarmasin.html. [Accessed: 20-Jan-2018].

3. A. A. Kasim and A. Harjoko, "Klasifikasi Citra Batik Menggunakan Jaringan Syaraf Tiruan Berdasarkan Gray Level Co- Occurrence Matrices ( GLCM )," Semin. Nas. Apl. Teknol. Inf. Yogyakarta, 21 Juni 2014, pp. 7-13, 2014.

4. A. E. Minarno and N. Suciati, "Batik Image Retrieval Based on Color Difference Histogram and Gray Level Co-Occurrence Matrix," TELKOMNIKA (Telecommunication Comput. Electron. Control., vol. 12, no. 3, p. 597, Sep. 2014.

5. A. E. Minarno, Y. Munarko, A. Kurniawardhani, F. Bimantoro, and N. Suciati, "Texture feature extraction using co-occurrence matrices of sub-band image for batik image classification," in 2014 2nd International Conference on Information and Communication Technology, ICoICT 2014, 2014, pp. 249-254. 
6. C. S. K. Aditya, M. Hani'Ah, R. R. Bintana, and N. Suciati, "Batik classification using neural network with gray level co-occurence matrix and statistical color feature extraction," in Proceedings of 2015 International Conference on Information and Communication Technology and Systems, ICTS 2015, 2016, pp. 163-167.

7. Q. Chen and E. Agu, "Exploring Statistical GLCM Texture Features for Classifying Food Images," in 2015 International Conference on Healthcare Informatics, 2015, pp. 453-453.

8. M. D. ROSYADI, "PENGENALAN MOTIF DASAR PADA KAIN SASIRANGAN MENGGUNAKAN METODE TEMPLATE MATCHING,” Technol. J. Ilm., vol. 8, no. 2, pp. 53-61, 2017.

9. I. Setyawan, I. K. Timotius, and M. Kalvin, "Automatic batik motifs classification using various combinations of SIFT features moments and k-Nearest Neighbor," in Proceedings - 2015 7th International Conference on Information Technology and Electrical Engineering: Envisioning the Trend of Computer, Information and Engineering, ICITEE 2015, 2015, pp. 269-274.

10. N. Suciati, W. A. Pratomo, and D. Purwitasari, "Batik motif classification using colortexture-based feature extraction and backpropagation neural network," in Proceedings - 2014 IIAI 3rd International Conference on Advanced Applied Informatics, IIAI-AAI 2014, 2014, pp. 517-521.

11. C. S. K. Aditya, M. Hani'Ah, R. R. Bintana, and N. Suciati, "Batik classification using neural network with gray level co-occurence matrix and statistical color feature extraction," in Proceedings of 2015 International Conference on Information and Communication Technology and Systems, ICTS 2015, 2016, pp. 163-167.

12. R. Azhar, D. Tuwohingide, D. Kamudi, Sarimuddin, and N. Suciati, "Batik Image Classification Using SIFT Feature Extraction, Bag of Features and Support Vector Machine," Procedia Comput. Sci., vol. 72, pp. 24-30, Jan. 2015.

13. S. Seman, Sasirangan: kain khas Banjar. Lembaga Pengkajian dan Pelestarian, Budaya Banjar, Kalimantan Selatan, 2008.

14. A. Vedaldi and B. Fulkerson, "VLFeat: An open and portable library of computer vision algorithms (2008).” 2012. 